\title{
Nova Gestão Pública e Gestão Democrática da Escola: as experiências da primeira fase de implementação do Programa Ensino Médio Inovador
}

\author{
New Public Management and Democratic Management of the School: \\ the experiences of the first phase of implementation of the \\ Innovative High School Program \\ Nueva Gestión Pública y Gestión Democrática de la Escuela: \\ las experiencias de la primera fase de implementación del \\ Programa Educación Secundaria Innovadora
}

\author{
https://orcid.org/0000-0002-8193-2373 \\ Universidade Federal do Paraná \\ Faculdade de Educação \\ Educação Profissional e Tecnológica \\ Paraná, PR, Brasil \\ MONICA RIBEIRO DA SILVA \\ https://orcid.org/0000-0002-1729-8742 \\ Universidade Federal do Paraná \\ Faculdade de Educação \\ Núcleo Observatório do Ensino Médio \\ Paraná, PR, Brasil
}

\begin{abstract}
Resumo: $\mathrm{O}$ artigo analisa as implicações das abordagens de gestão democrática e de gestão gerencial na implementação do Programa Ensino Médio Inovador em sua primeira fase. Os dados foram obtidos por meio de questionário aplicado em 2006 escolas. Para a sua análise foi utilizada a técnica de análise de conteúdo e o referencial teórico dos modelos de gestão. O estudo evidenciou que as experiências mais próximas das intenções do Programa estiveram associadas a vivências participativas. Detectou que o principal entrave à formação integral foi a adoção de práticas inspiradas na abordagem de gestão gerencial focadas na padronização, na adaptação e no controle.
\end{abstract}

Palavras-chave: Ensino Médio; Programa Ensino Médio Inovador; Gestão Democrática; Nova Gestão Pública. 
Abstract: The article analyzes the implications of democratic and management approaches in the implementation of the Programa Ensino Médio Inovador (Innovative High School Program) in its first phase. The data was obtained through a questionnaire applied to 2006 schools. The content analysis technique and the theoretical framework of management models were used for its analysis. The study showed that the experiences closest to the Program's intentions were associated with participatory experiences. It was found that the main obstacle to integral training was the adoption of practices inspired by the management approach focused on standardization, adaptation, and control.

Keywords: High school; Innovative High School Program; Democratic management; New Public Management.

Resumen: El artículo analiza las implicaciones de los enfoques de gestión democrática y gestión gerencial en la implementación del Programa Educación Secundaria Innovadora en su primera fase. Los datos fueron obtenidos a través de un cuestionario aplicado en 2006 escuelas. Para su análisis se utilizó la técnica de análisis de contenido y el marco teórico de los modelos de gestión. El estudio mostró que las experiencias más cercanas a las intenciones del Programa estaban asociadas a experiencias participativas. Se verificó que el principal obstáculo para la formación integral fue la adopción de prácticas inspiradas en el enfoque de gestión gerencial centradas en la estandarización, adaptación y control.

Palabras clave: Educación Secundaria; Programa Educación Secundaria Innovadora; Gestión democrática; Nueva administración pública.

\section{INTRODUÇÃO}

O Ensino Médio, última etapa da educação básica, tem se configurado nas políticas públicas brasileiras como um objeto de grande disputa por parte de redes de relações econômicas, sociais e políticas. Nesse contexto, o presente artigo analisou as implicações de distintos modelos de gestão da educação nos processos formativos de Ensino Médio na fase inicial de implementação do Programa Ensino Médio Inovador (ProEMI), no período de 2009 a 2013². O objetivo principal foi o de caracterizar os modelos de gestão educacional que disputavam a organização de instituições públicas de Ensino Médio no período, e relacioná-los a valores e interesses dos grupos sociais que protagonizavam tais modelos.

Tomou-se como hipótese que a perspectiva gerencial se configuraria como um fator a dificultar a reformulação curricular na perspectiva prevista no Programa² e explicitada no Parecer CNE/CP n. 11, de 30 de junho de 2009, que

\footnotetext{
$1 \quad \mathrm{O}$ problema de pesquisa surgiu da participação no projeto (omitido), cujos resultados são apresentados no relatório (omitido).

2 O ProEMI foi instituído por meio da Portaria n. 971, de 09 de outubro de 2009, com vistas a induzir mudanças curriculares alinhadas com essas diretrizes e com as matrizes de referência do novo Exame Nacional do Ensino Médio (MEC, 2011b).
} 
tratava da proposta de experiência curricular inovadora do Ensino Médio, bem como na Resolução CNE/SEB n. 2, de 30 de janeiro de 2012, que estabelecia as Diretrizes Curriculares Nacionais do Ensino Médio (DCNEM). A hipótese formulada decorreu dos enunciados presentes nesses documentos, que afirmavam a necessidade de ampla participação da comunidade escolar nos projetos de reformulação curricular das escolas, bem como do envolvimento estudantil com vistas à formação para a autonomia.

A pesquisa abrangeu o total das escolas que implementaram o ProEMI no período analisado: 2006 escolas distribuídas em 24 estados e no Distrito Federal. No país, apenas dois estados não haviam implantado o Programa até abril de 2013: Minas Gerais, na região Sudeste, e Alagoas, na região Nordeste. Do total de instituições de ensino que aderiram ao ProEMI, 893 escolas responderam ao questionário. Esse número representa $44,5 \%$ das escolas que aderiram ao Programa no período analisado, sendo que, em algumas instituições, mais de um professor respondeu ao questionário, totalizando 1282 professores respondentes.

O percentual de questionários respondidos variou entre as regiões: na região Sul, 64,6\% das escolas responderam aos questionários; na região Sudeste, $51,7 \%$; na região Nordeste, $40 \%$; na região Centro-Oeste, $36,6 \%$ e; na região Norte, $30 \%$. Dentre os fatores que explicam uma menor incidência de respostas nas regiões Norte, Centro-Oeste e Nordeste, está o acesso mais restrito das escolas dessas regiões aos serviços de internet banda larga e mesmo ao correio convencional.

Com o fim de verificar a relação dos novos modelos de gestão da educação com as experiências curriculares implementadas, foi realizada a análise qualitativa dos relatos das vivências docentes a partir da técnica de Análise de Conteúdo (BARDIN, 1977). As seguintes categorias de análise foram adotadas: a adesão ou não a tecnologias propostas no Guia de Tecnologias Educacionais do MEC; o foco das práticas curriculares - no processo ou no produto; a organização do planejamento e da formação continuada dos professores; a abordagem de protagonismo estudantil; e as relações entre a escola e a comunidade.

A próxima seção destina-se à revisão de literatura sobre a gestão do Ensino Médio na relação com as novas abordagens de gestão pública e à análise comparativa entre as abordagens de gestão democrática e gerencial no que se refere às experiências formativas relatadas no período inicial da implementação do ProEMI. 


\section{AS EXPERIÊNCIAS CURRICULARES DO PROGRAMA ENSINO MÉDIO INOVADOR NO CONTEXTO DAS NOVAS ABORDAGENS DE GESTÃO PÚBLICA}

Nas últimas décadas se verifica no Brasil uma disputa em torno de uma nova abordagem de Administração Pública em que se destacam duas vertentes - a Administração Pública Gerencial ${ }^{3}$ e a Administração Pública Societal evidenciando que a nova abordagem de gestão pública está em construção (PAULA, 2005). A ênfase da primeira recai na dimensão econômico-financeira e institucional-administrativa, e a da segunda na dimensão sociopolítica. Essa polaridade reflete a clássica dicotomia que circunda a gestão pública e que se constitui em um dos maiores desafios da sociedade e dos gestores públicos no que tange à Administração Pública na atualidade (PAULA, 2007). De acordo a autora, uma crítica ao modelo gerencialista de Administração Pública é a separação entre questões técnicas e políticas, não se comprometendo com a dimensão sociopolítica das políticas públicas, como com a organização da complexa dinâmica de participação social na sociedade democrática.

A gestão da educação, e em particular do Ensino Médio, não escapa a esse conflito de perspectivas. A Constituição da República Federativa do Brasil de 1988, no Artigo 206, inciso VI; e a Lei de Diretrizes e Bases da Educação Nacional (LDBEN) n. 9.394/1996, Artigo $3^{\circ}$, inciso VIII, preconizam que o ensino público deve ser ministrado com base no princípio da gestão democrática. Por conseguinte, os debates sobre a gestão escolar focalizam esse princípio e as formas de sua efetivação. No entanto, subsistem diferentes modelos de gestão que, não podendo negar o princípio constitucional da democracia, atribuem a ela diferentes sentidos que variam de acordo com os interesses da diversidade de atores que incidem na formulação, implementação e avaliação das políticas educacionais.

De acordo com Cabral Neto e Castro (2011), algumas das manifestações do gerencialismo no setor público são: 1) a ênfase nos processos e resultados das políticas públicas, adotando a eficiência, eficácia e produtividade como matriz de referência e mecanismos como modelos de avaliação de desempenho; 2) orientações, métodos, técnicas, instrumentos ou tecnologias apresentadas como politicamente neutras; e 3) a utilização do discurso de participação e autonomia. No campo educacional, os autores destacam programas e projetos dos últimos

3 Esse modelo de gestão tem sido difundido como Nova Gestão Pública, pela similaridade com a expressão e com os princípios da New Public Management, do Reino Unido. 
governos que se alinham com o gerencialismo, tais como o Programa de Desenvolvimento Educacional (PDE), o Plano Estratégico das Secretarias (PES) e o Plano de Desenvolvimento da Escola (PDE-Escola).

Por outro lado, a perspectiva democrática pressupõe a compreensão da educação como um direito social, a busca pela sua qualidade, a descentralização do poder, a autonomia e a participação dos diversos agentes locais interessados na ação educativa para o planejamento, a execução e a avaliação das ações da escola. As estratégias para o fortalecimento dessa forma de gestão são a participação da comunidade escolar na elaboração do projeto político-pedagógico e no conselho escolar (CABRAL NETO; CASTRO, 2011).

Adicionalmente, diversos elementos da cultura escolar intervêm na organização do trabalho pedagógico no Ensino Médio e, em especial, no seu currículo, que é o espaço central pelo qual se efetiva a função da escola. A identificação desses elementos requer o conhecimento das relações efetivamente praticadas na escola. Com base no entendimento de que parte desses processos se manifesta na prática cotidiana dos professores, busca-se identificar nos relatos sobre as suas experiências curriculares mais significativas elementos que se relacionam com os processos de gestão escolar. A análise se estruturou a partir de cinco eixos: a adesão ou não a tecnologias propostas no Guia de Tecnologias Educacionais do MEC; o foco das práticas curriculares - no processo ou no produto; a organização do planejamento e da formação continuada dos professores; a abordagem de protagonismo estudantil; e as relações entre a escola e a comunidade. Na sequência, cada um desses eixos é caracterizado e discutido em relação aos dados coligidos e aos modelos de gestão democrática e gerencial.

\section{A ADESÃO OU NÃO A PROGRAMAS DO GUIA DE TECNOLOGIAS EDUCACIONAIS DO MEC}

Os Guias de Tecnologias Educacionais (MEC, 2009; 2011) foram desenvolvidos no âmbito do PDE-Escola, que segundo o MEC visa alcançar uma educação pública de qualidade mediante a elevação do Índice de Desenvolvimento da Educação Básica (IDEB), elaborado pelo Instituto Nacional de Estudos e Pesquisas Educacionais Anísio Teixeira (INEP).

O PDE foi apresentado à sociedade brasileira em março de 2007 e lançado oficialmente no mês seguinte de modo simultâneo à promulgação do Decreto n. 6.094/2007 que dispõe sobre a implementação do Plano de Metas Compromisso Todos pela Educação. O "Compromisso Todos pela Educação", de acordo com Saviani (2007), foi lançado por um grupo de empresários e se embasa em uma 
lógica de mercado que se equipara a uma espécie de "pedagogia de resultados" em que o governo define os instrumentos de avaliação dos produtos e, como desdobramento, exige o ajuste às demandas das empresas.

Para aderir ao PDE foi atribuída às escolas a incumbência de desenvolver o PDE-Escola. Trata-se de um programa de apoio à gestão escolar com recursos financeiros específicos para esse fim e que se caracteriza como uma ferramenta gerencial destinada à elaboração do planejamento estratégico da escola para a melhoria do ensino (MEC, 2006). Cabral Neto e Castro (2011) perceberam que a imposição de instrumentos do gerencialismo para a efetivação do financiamento, como a elaboração do planejamento estratégico induzido por meio do PDEEscola, fragiliza a gestão democrática e a sua incorporação mais efetiva na cultura escolar, relegando à menor importância a elaboração do projeto políticopedagógico, fundado nos princípios da gestão democrática.

Os Guias de Tecnologias Educacionais contam com tecnologias elaboradas pelo MEC e por instituições e/ou empresas públicas ou privadas, sendo divididos em seis blocos: 1) Gestão da Educação; 2) Ensino-Aprendizagem; 3) Formação dos Profissionais da Educação; 4) Educação Inclusiva; 5) Portais Educacionais; e 6) Diversidade e Educação de Jovens e Adultos. As tecnologias externas foram selecionadas pelo MEC a partir de editais de chamamento público para préqualificação de tecnologias, como o Aviso de Chamamento Público MEC/SEB/ SECAD/SEED/SEESP n. 1/2009 e o Edital n. 1, de 09 de dezembro de 2011, do Gabinete do Ministro da Educação.

O Instituto Unibanco obteve pré-qualificação para a ação intitulada Programa Jovem de Futuro (PJF). A ação foi destinada ao Ensino Médio para ser realizada em parceria com as Secretarias de Educação e escolas. De acordo com os Guias de Tecnologias Educacionais, o objetivo do PJF seria o de influenciar a gestão escolar no Ensino Médio e, de modo específico:

Este projeto visa, principalmente, oferecer às escolas públicas de Ensino Médio regular apoio técnico e financeiro para a concepção, a implantação e avaliação de um plano de melhoria da qualidade da dinâmica de funcionamento escolar, com duração de três anos, de forma a aumentar significativamente o rendimento dos alunos, nos testes padronizados de Língua Portuguesa e Matemática, e diminuir os índices de evasão/abandono (MEC, 2009, p. 35; MEC, 2011, p. 34). 
A tecnologia PJF se baseia no conceito de Gestão Escolar para Resultados (GEpR), uma concepção de caráter gerencial:

O projeto Jovem de Futuro utiliza o conceito de Gestão Escolar para Resultados (GEpR). A ideia básica parte do pressuposto de que não existe organização, sobretudo uma instituição voltada para o interesse público, sem uma qualificação técnica e social da gestão. Nesse sentido, busca apresentar para os gestores escolares estratégias e instrumentos que tornam seu trabalho mais eficiente, criativo e produtivo. Seus princípios orientam para um trabalho com foco nos resultados positivos de ensino e de aprendizagem. Tal proposta sugere a integração de diferentes processos e ferramentas de gestão escolar, a mobilização de recursos humanos, a articulação de recursos técnicos, materiais e financeiros, a divisão de responsabilidades, a adoção de sistemas de informação voltados para o monitoramento, controle e avaliação, a utilização de programas de comunicação para garantir ampla adesão da comunidade às ações da escola, sempre tendo em vista a conquista de melhores resultados na aprendizagem dos alunos. (INSTITUTO UNIBANCO, 2016, s.p.) ${ }^{4}$.

Nessa perspectiva, o termo tecnologia é associado a ferramentas, instrumentos e técnicas politicamente neutras, de caráter racional e universal, com vistas a um trabalho eficiente que garanta o alcance das metas estabelecidas. Essa visão caracteriza uma abordagem instrumentalista de tecnologia que tem reflexos na gestão escolar. Apesar de se afirmar nos Guias de Tecnologias Educacionais do MEC $(2009 ; 2011)$ que o uso de uma tecnologia só faz sentido se houver comprometimento com a gestão democrática, uma tecnologia de caráter instrumental se configura como um entrave a esta forma de gestão, pois não há participação dos sujeitos da escola no desenho da tecnologia, mas apenas na sua execução de acordo com valores pré-estabelecidos pelos seus autores.

A competência técnica para a formulação de estratégias inovadoras de organização curricular, nesse caso, é atribuída ao Instituto Unibanco. Este, além de disponibilizar a tecnologia oferecia formação continuada aos gestores, coordenadores pedagógicos e professores das escolas como suporte para a sua implementação. Esse aspecto entra em contradição com os pressupostos da proposta de criação do ProEMI, que considera essencial o compromisso político e a competência técnica dos professores, o respeito às diversidades de jovens e o zelo pela autonomia da escola na formulação do seu Projeto Político-Pedagógico (BRASIL, 2009a).

Na pesquisa realizada, o PJF foi mencionado por professores dos estados de São Paulo, Ceará, Goiás, Mato Grosso do Sul e Pará.

4 Disponível em: <http://www.institutounibanco.org.br/jovem-de-futuro/oque-e>. Acesso em: 02 fev. 2016.

472 - Rev. Bras. Polít. Adm. Educ. - v. 37, n. 1, p. 466 - 485, jan./abr. 2021 


\section{O FOCO DAS PRÁTICAS CURRICULARES - PROCESSO OU PRODUTO}

A ênfase no desenvolvimento das atividades curriculares na escola varia de acordo com o modelo de gestão em que são concebidas, ora destacando as mudanças necessárias e/ou realizadas no processo de ensino-aprendizagem, ora salientando os produtos ou resultados esperados e/ou alcançados, conforme demonstrado no Quadro 1.

\section{Quadro 01 - Foco das práticas curriculares - processo ou produto}

\begin{tabular}{|c|c|}
\hline Gestão Democrática & Gestão Gerencial \\
\hline $\begin{array}{l}\text { Foco no aprimoramento do processo de ensino-aprendizagem } \\
\text { por meio de: } \\
\text { - preocupação com a compreensão e apropriação do } \\
\text { conhecimento escolar nos mais diversos componentes } \\
\text { curriculares pelo máximo de alunos; } \\
\text { - uso de metodologias que contemplam os interesses dos } \\
\text { estudantes e favorecem a participação do aluno nas atividades } \\
\text { curriculares; } \\
\text { - aquisição ou construção e utilização de instrumentos que } \\
\text { possibilitam a aplicação empírica de conceitos teóricos } \\
\text { trabalhados nas aulas; } \\
\text { - realização de experiências de laboratório para aplicação de } \\
\text { conceitos teóricos; } \\
\text { - desenvolvimento de projetos que relacionam o contexto local } \\
\text { com conhecimentos de diferentes componentes curriculares; } \\
\text { - articulação entre componentes curriculares de uma mesma } \\
\text { área de conhecimento, de áreas de conhecimento distintas e/ou } \\
\text { destas com os macrocampos e entre macrocampos; } \\
\text { - satisfação de professores e alunos com as metodologias } \\
\text { desenvolvidas nas aulas e os novos aprendizados; } \\
\text { - o ensino de Língua Portuguesa e Matemática frequentemente } \\
\text { é integrado com outros componentes curriculares ou } \\
\text { macrocampos para uma aprendizagem mais significativa e } \\
\text { prazerosa, por meio de estratégias como a comparação entre } \\
\text { um livro e um filme em júri simulado, elaboração de peças de } \\
\text { teatro ou dramatizações sobre obras literárias, produção de } \\
\text { vídeos, utilização de jogos e outras; } \\
\text { - aulas de reforço ministradas pelos professores para os alunos } \\
\text { que têm mais dificuldades. }\end{array}$ & $\begin{array}{l}\text { Ênfase na melhoria dos produtos/ resultados de rendimento } \\
\text { escolar por meio de: } \\
\text { - preocupação com o desempenho dos alunos em avaliações } \\
\text { externas, como o ENEM e as avaliações estaduais (SAERJ, } \\
\text { SARESP, SPAECE e SIPAVE); } \\
\text { - aulas preparatórias, simulados e outras estratégias para } \\
\text { motivar os alunos para as provas de avaliação externa; } \\
\text { - a frequência e o rendimento escolar são critérios para a } \\
\text { participação em determinados projetos, favorecendo os } \\
\text { alunos que já se apresentam em vantagem em relação ao } \\
\text { conhecimento escolar; } \\
\text { - priorização do letramento em Língua Portuguesa e } \\
\text { Matemática por meio de aulas de reforço, aulas preparatórias } \\
\text { para as provas, competições entre alunos e turmas, concursos } \\
\text { de redação e de leitura, olimpíadas, entre outras estratégias; } \\
\text { - auxílio nas dificuldades de Língua Portuguesa e Matemática } \\
\text { por meio de alunos monitores; } \\
\text { - monitoramento de resultados; } \\
\text { - emprego de termos próprios do gerencialismo, como metas, } \\
\text { eficácia, eficiência e resultados. }\end{array}$ \\
\hline
\end{tabular}

FONTE: Autora 1, 2016.

As práticas curriculares derivadas da gestão democrática caracterizam-se pelo empenho em garantir que todos os alunos se apropriem do conhecimento escolar nos mais diversos componentes curriculares, buscando reduzir as desigualdades com que os alunos iniciam o processo de ensino-aprendizagem. Para tanto, uma das características que diferencia substancialmente as práticas curriculares nessa perspectiva é a consideração dos interesses e necessidades dos jovens estudantes como ponto de partida para o planejamento docente ou para o redimensionamento deste planejamento. 
Quanto aos procedimentos didáticos, os professores revelaram que utilizavam instrumentos adquiridos pelas escolas ou que produziam com os alunos instrumentos que possibilitavam a aplicação empírica de conceitos teóricos trabalhados nas aulas. Também destacaram a realização de experiências em laboratórios de ciências e outros. Esse estímulo às atividades teóricopráticas integra as proposições curriculares do ProEMI (BRASIL, 2009a). Outra característica importante do ponto de vista da gestão democrática se referia ao desenvolvimento de projetos que relacionam conhecimentos de diferentes componentes curriculares com o contexto local, articulando o conhecimento escolar com as experiências de vida e de trabalho da comunidade em que se insere a escola, perspectiva estimulada pelo ProEMI.

A articulação entre as áreas do conhecimento foi identificada como capaz de propiciar a efetivação de experiências curriculares que se aproximavam da perspectiva de formação humana integral que o ProEMI buscava estimular. Foram incorporadas novas dimensões de formação com ênfases diferenciadas, dependendo do diálogo com os universos juvenis. Um exemplo é a produção coletiva de um filme curta metragem que propiciou o desenvolvimento de um novo olhar sobre as produções cinematográficas.

As experiências curriculares de viés gerencial, por sua vez, enfatizaram a melhoria dos produtos/resultados de rendimento escolar. Os professores imersos nessa dinâmica ressaltavam a preocupação com o desempenho dos alunos em avaliações externas, como o ENEM e as avaliações estaduais: Sistema de Avaliação da Educação do Estado do Rio de Janeiro (SAERJ); Sistema de Avaliação de Rendimento Escolar do Estado de São Paulo (SARESP); Sistema Permanente de Avaliação da Educação Básica do Ceará (SPAECE); e Sistema Paraense de Avaliação Educacional (SIPAVE).

$\mathrm{Na}$ análise do conjunto de experiências percebeu-se que os professores de escolas focadas nas avaliações externas criavam ou inovavam pouco, enfocando o currículo de caráter fragmentado, repetitivo e enciclopédico. Com base em Krawczyk (2014) é possível reiterar que a adequação às exigências e prioridades das avaliações externas limita a autonomia pedagógica, já que as influências externas nem sempre são compatíveis com os interesses dos sujeitos da instituição escolar. Essa limitação da autonomia parece se desdobrar na redução da liberdade para a criação do novo. 


\section{ORGANIZAÇÃO DO PLANEJAMENTO E DA FORMAÇÃO CONTINUADA}

A organização do planejamento e da formação continuada também se estabelecia de formas distintas dependendo do modelo de gestão, como ilustra o Quadro 2:

\section{Quadro 2 - Organização do planejamento e formação continuada}

\begin{tabular}{|c|c|}
\hline Gestão Democrática & Gestão Gerencial \\
\hline  & $\begin{array}{l}\text { - O planejamento dos professores é fortemente influenciado } \\
\text { pelo PJF, suas metodologias e materiais didáticos, enfrentando } \\
\text { adesões e resistências. } \\
\text { - Falta de consulta aos docentes e outros segmentos da } \\
\text { comunidade escolar sobre a implementação do ProEMI. } \\
\text { - Discussão das dificuldades do trabalho realizado na escola e } \\
\text { definição de metas. } \\
\text { - Discurso híbrido quanto aos referenciais orientadores das } \\
\text { práticas pedagógicas, como os do ProEMl e PJF. } \\
\text { - Participação em reuniões pedagógicas e busca de maior } \\
\text { articulação entre as disciplinas. } \\
\text { - Suporte financeiro para o desenvolvimento de ações } \\
\text { pedagógicas. } \\
\text { - Planejamento de aulas diferenciadas. } \\
\text { - Formação continuada vinculada ao PJF, do Instituto Unibanco, } \\
\text { que se constitui em uma espécie de treinamento para implantar } \\
\text { metodologias pensadas externamente à escola. } \\
\text { - Na descontinuidade da parceria com o Instituto Unibanco } \\
\text { em São Paulo, os professores ficaram desinformados e } \\
\text { desorientados sobre as ações do ProEMl. } \\
\text { - Discussão de resultados da avaliação em larga escala. } \\
\text { - Dificuldades relacionadas ao acúmulo de funções, à } \\
\text { sobrecarga de trabalho, à falta de professor articulador do } \\
\text { ProEMl e à rotatividade de professores. }\end{array}$ \\
\hline
\end{tabular}

FONTE: Autora 1, 2016. 
De modo alinhado com a perspectiva democrática, em alguns estados, entre eles Paraíba, Rio Grande do Sul e Santa Catarina, foram observadas experiências de planejamento semanal coletivo por professores de uma ou mais áreas do conhecimento como parte da carga horária de trabalho. Essa organização favorecia o trabalho interdisciplinar e as trocas de experiências entre professores. Em muitos casos os períodos de planejamento eram acompanhados pelo professor articulador, por coordenadores pedagógicos e/ou diretores das escolas.

As condições propiciadas pelo ProEMI, como a maior disponibilidade de recursos financeiros, materiais e tecnológicos para as ações pedagógicas inovadoras, a dedicação exclusiva do professor a uma escola e a maior carga horária destinada ao planejamento foram destacadas como facilitadoras do planejamento de atividades integradoras. A descentralização de recursos financeiros também foi enfatizada com relação à organização da formação continuada dos professores, por viabilizar a definição dos temas e a escolha dos ministrantes pela escola de acordo com as suas necessidades.

Nas experiências destacadas pelos professores foram evidenciados também processos de organização do planejamento e da formação continuada, marcados pela perspectiva gerencial. Essas características se manifestaram com mais força em escolas que aderiram ao PJF. Nos limites da sua autonomia e nas possibilidades de sua resistência, os professores sinalizaram dificuldades do trabalho realizado na escola e a preocupação com os resultados das avaliações em larga escala. Foi possível identificar, ainda, discursos híbridos como "ProEMI/ PJF", como se os pressupostos e referenciais das práticas pedagógicas fossem idênticos.

No contexto do PJF, a formação continuada adquiriu o duplo caráter de reforçar a heteronomia e de ser instrumento de valorização docente, constituindo-se em uma espécie de treinamento para implantar metodologias pensadas externamente à escola com o uso de materiais a elas associados. Os sujeitos docentes, deslocados das condições de autoria, ora reconheceram os "cardápios de metodologias" como caminhos certos e seguros para o alcance das metas estabelecidas, ora exercitaram a crítica sobre a sua articulação com as reais necessidades e interesses da comunidade escolar. 


\section{A ABORDAGEM DE PROTAGONISMO JUVENIL}

O desenvolvimento do protagonismo juvenil foi uma das ações previstas no programa para inovações curriculares, conforme o Parecer CNE/ CP n. 11/2009. Também o Parecer CNE/CEB n. 5/2011, ao tratar da gestão democrática, destacou a importância do protagonismo dos estudantes atribuindolhe o seguinte sentido:

Como sujeitos de direitos, os estudantes devem tomar parte ativa nas discussões das regras da escola, sendo estimulados à auto-organização e devem ter acesso a mecanismos que permitam se manifestar sobre o que gostam e o que não gostam na escola e a respeito da escola a que aspiram. (BRASIL, 2011a, p. 34).

A Resolução CNE/CEB n. 2/2012, Art. 16, XXI, determinava que o Projeto Político-Pedagógico das escolas de Ensino Médio deveria considerar a "participação social e protagonismo dos estudantes, como agentes de transformação de suas unidades de ensino e de suas comunidades". Adicionalmente, o Art. 17, II, b, orientava os sistemas de ensino a promover mecanismos de participação da comunidade que possibilitassem a organização de atividades educacionais e socioculturais favoráveis à iniciativa, à autonomia e ao protagonismo social dos estudantes.

Assim como acontece com a apropriação do termo gestão democrática, o protagonismo juvenil também adquiriu diferentes sentidos e significados, conforme sintetizado no Quadro 3, a seguir:

\section{Quadro 3 - Protagonismo estudantil}

\begin{tabular}{|l|l|}
\hline \multicolumn{1}{|c|}{ Gestão Democrática } & \multicolumn{1}{|c|}{ Gestão Gerencial } \\
\hline - A participação dos alunos como sujeitos ativos no processo de ensino- & - Associação de metodologias do Instituto Unibanco, \\
aprendizagem é potencializada pela realização de aulas que consideram & como Agente Jovem, Valor do Amanhã e Superação \\
os seus interesses e as suas necessidades, gerando efeitos positivos na & na escola, com o protagonismo juvenil. Portanto, \\
sua relação com o professor, com a escola e com o conhecimento. & a participação dos estudantes é delimitada por \\
- Os estudantes não contemplados pelo ProEMl reivindicam seu direito de & metodologias definidas externamente à escola. \\
participação no programa. & - Desenvolvimento de ações solidárias pontuais, \\
- Os estudantes questionam as atividades desenvolvidas no ProEMl e & individuais ou coletivas, para desenvolver atividades \\
abandonam as aulas quando não são de seu interesse. & de manutenção da escola e de apoio a grupos \\
- As escolas estimulam a livre iniciativa, a mobilização e a organização & socialmente vulneráveis. \\
dos estudantes para a implantação do Grêmio Estudantil. & \\
- A incorporação de novos espaços e tempos educativos e a abertura da & \\
escola para a comunidade a partir de sua função social valoriza a criação & \\
de meios de participação e de produção de conteúdo pelos alunos. & \\
- O diálogo dos professores com os alunos proporciona, aos primeiros, & \\
um novo olhar sobre os jovens; e aos segundos, um maior entusiasmo & \\
pela aprendizagem e maior aproximação com a escola. & \\
\hline
\end{tabular}

FONTE: Autora 1, 2016. 
O discurso da participação ativa dos alunos, de acordo com Ferretti, Zibas e Tartuce (2004), não é novo, mas lembra processos de descontextualização e recontextualização, em que é aplicado a contextos, práticas e relações sociais distintos daqueles em que se originou. Como bem evidenciam os autores, a partir de análise de literatura e de documentos oficiais dos anos 90, o protagonismo juvenil é um conceito multifacetado, sujeito a diversas interpretações que atribuem à participação estudantil sentidos pedagógicos e políticos variados.

A análise das experiências de professores nos primeiros anos de implantação do ProEMI demonstrou a permanência dessas contradições. O primeiro grupo de experiências, caracterizadas como democráticas, incorpora algumas das dimensões induzidas pelo ProEMI, como a consideração das condições e dos interesses juvenis como ponto de partida do planejamento de ações da escola e dos professores. O diálogo dos professores com os alunos sobre as suas condições juvenis e expectativas em relação à escola proporcionou aos primeiros um novo olhar sobre os jovens e aos segundos, um maior entusiasmo pela aprendizagem e maior aproximação com a escola.

Outro aspecto que favorece a participação diz respeito à incorporação de novos espaços e tempos educativos e à abertura da escola para a comunidade a partir de sua função social. Nesse processo foi destacada a valorização dos meios de participação e de produção de conteúdo pelos alunos, bem como o estímulo à livre iniciativa, à mobilização e à organização dos estudantes para a implantação do Grêmio Estudantil.

Os depoimentos dos professores que acompanharam práticas dinamizadoras da efetiva participação dos estudantes reafirmaram o argumento de Dayrell e Carrano (2014) de que a experiência de participação ativa é educativa e formativa, podendo potencializar processos de aprendizagem mais amplos na escola. Quando os professores não oportunizavam espaços para a manifestação dos estudantes ou quando as visões dos estudantes não foram incorporadas nos modos de ação da escola, isso foi compreendido como fator de abandono do Programa. Do mesmo modo, em alguns casos, segundo os professores, os alunos reivindicavam seu direito de participação no Programa porque se sentiam excluídos, por um lado, e atraídos, por outro lado.

Outro grupo de experiências incluiu as escolas que aderiram ao PJF, do Instituto Unibanco, e que revelaram práticas de gestão gerencialistas. Nessas escolas a participação dos estudantes era delimitada por metodologias definidas externamente à escola, como Agente Jovem, Valor do Amanhã e Superação na escola. Nessas propostas, o protagonismo juvenil estava associado frequentemente com ações solidárias pontuais, individuais ou coletivas, para desenvolver atividades de manutenção da escola e de apoio a grupos socialmente vulneráveis: na escola 
(alunos com dificuldades na aprendizagem dos conteúdos); ou em seu entorno (instituições de acolhimento de idosos, crianças ou outras). Nessas experiências o enfoque consistia na criação de uma sensibilidade solidária que gerava satisfação individual e integração entre os membros envolvidos na ação.

\section{AS RELAÇÕES ENTRE A ESCOLA E A COMUNIDADE}

A articulação da escola com as famílias e a comunidade para a consecução da gestão democrática está estabelecida na LDBEN n. 9.394/1996, nos artigos 12, 13 e 14. Ela representa uma responsabilidade dos profissionais responsáveis pela gestão de unidades escolares e dos sistemas de ensino. A forma pela qual as escolas efetivam essa articulação, contudo, também variou de acordo com os modelos de gestão adotados na prática, como ilustra o Quadro 4:

\section{Quadro 4 - Relação escola - comunidade}

\begin{tabular}{|c|c|}
\hline Gestão Democrática & Gestão Gerencial \\
\hline $\begin{array}{l}\text { - Maior aproximação, articulação e comunicação da escola com os } \\
\text { diversos segmentos da comunidade escolar, que favorece a relação dos } \\
\text { estudantes com a escola e o conhecimento. } \\
\text { - Discussão da avaliação interna e externa da escola e elaboração de } \\
\text { planos para melhorar a qualidade do ensino como parte da elaboração } \\
\text { coletiva e autônoma do Projeto Político-Pedagógico. } \\
\text { - Apreciação de trabalhos dos alunos pelos diversos segmentos da } \\
\text { comunidade escolar. } \\
\text { - O espaço educativo expande-se para além da escola com atividades } \\
\text { planejadas a partir da sua função social que, muitas vezes, são } \\
\text { integradas ao currículo e dialogam com as condições de vida dos } \\
\text { moradores. Assim, ocorrem atividades pedagógicas no entorno próximo } \\
\text { à escola ou município, nas universidades, em órgãos públicos, empresas } \\
\text { e outros locais. } \\
\text { - A aproximação da escola com as famílias dos alunos contribui para } \\
\text { combater o abandono escolar. } \\
\text { - As adesões e resistências das famílias ao ProEMI reforçam a } \\
\text { importância do envolvimento das famílias dos alunos em todas as fases } \\
\text { da implantação do programa. } \\
\text { - O desenvolvimento de ações pedagógicas e solidárias junto a entidades } \\
\text { locais. }\end{array}$ & $\begin{array}{l}\text { - Maior aproximação entre escola e comunidade, em } \\
\text { especial, uma maior integração entre professores, } \\
\text { gestores, alunos e pais de alunos, aspecto atribuído à } \\
\text { metodologia PJF. } \\
\text { - Participação da comunidade na manutenção e } \\
\text { limpeza da escola, com base em metodologias do } \\
\text { Instituto Unibanco. } \\
\text { - Discussão da avaliação interna e externa da escola } \\
\text { e elaboração de planos para melhorar a qualidade do } \\
\text { ensino de acordo com as orientações do PJF. }\end{array}$ \\
\hline
\end{tabular}

FONTE: Autora 1, 2016.

Nas últimas décadas as relações entre a escola e as famílias se tornaram mais intensas, levando ao reconhecimento da necessidade de um diálogo mais efetivo entre as duas instituições, a mudanças nessas instâncias de socialização e a novos contornos na relação entre elas (NOGUEIRA, 2005).

Nessa linha de pensamento, uma das primeiras dimensões a considerar em relação ao ProEMI é que a sua implementação afetava o cotidiano das famílias. A frequência dos alunos à escola em período integral, em todos ou em alguns dias 
da semana, ou a extensão da carga horária em um dos turnos afetava a rotina das famílias e dos jovens, em particular. Assim, o diálogo com os jovens e as suas famílias sobre a implementação era condição essencial para a gestão democrática.

A segunda dimensão a analisar são os contornos dessa relação. Nogueira (2005) identifica três grandes tendências na relação entre família e escola: 1) uma maior aproximação entre as duas instâncias com a multiplicação e diversificação dos contatos formais e informais; 2) a individualização da relação; e 3) a redefinição dos papéis das duas instâncias, ainda que sem fronteiras claramente definidas - a escola não se limita à atribuição de desenvolvimento intelectual dos alunos e a família começa a requerer o direito de intervir nas questões de ordem pedagógica. Todas essas tendências foram observadas nos relatos dos professores com relação ao ProEMI, sendo que o conteúdo da relação depende das abordagens de gestão. Em relação à primeira tendência, a maior aproximação da escola com os diversos segmentos da comunidade escolar (e não apenas com a família) foi destacada em experiências que se orientavam por ambas as abordagens de gestão, mas com contornos distintos.

Por um lado, nas experiências marcadas pela gestão democrática verificouse maior ênfase sobre os efeitos positivos da articulação e comunicação entre a escola e a comunidade na relação dos estudantes com a escola e o conhecimento como, por exemplo, no combate ao abandono escolar. Por outro lado, nas experiências de viés gerencial atreladas ao PJF destacou-se a integração pessoal entre professores, gestores, alunos e pais de alunos.

No que se refere à segunda tendência, a aproximação entre a escola e a comunidade reforçada pelo ProEMI foi compreendida como processo de individualização, principalmente, em virtude do maior tempo dos alunos na escola e de novas oportunidades criadas para a participação das famílias.

É, no entanto, quanto à terceira tendência sobre as relações entre a escola e a família, apontada por Nogueira (2005), que se observam as mudanças mais significativas proporcionadas pelo ProEMI. Em experiências de ambas as abordagens de gestão (democrática e gerencial), a escola abria espaços para a participação dos pais em assuntos de natureza pedagógica, mas o fazia sob concepções e formas distintas. Como exemplo, na gestão democrática, a discussão da avaliação interna e externa da escola e a elaboração de planos para melhorar a qualidade do ensino realizava-se no contexto da elaboração coletiva e autônoma do projeto político-pedagógico. Nessa dinâmica, os sujeitos são coautores da apresentação, análise, discussão e definição das propostas de melhoria da qualidade do ensino, em especial por meio das instâncias colegiadas. Já, na gestão gerencial, esse processo se orientava pelas ações pré-definidas nas metodologias do Instituto Unibanco, como parte da execução do PJF. Pode-se inferir a partir das experiências 
analisadas que ocorreu um processo de convencimento da comunidade escolar, em especial das famílias, para saborear as metodologias propostas como caminho certo e seguro para obter melhores resultados no desempenho acadêmico dos alunos. Nesse sentido, a ação dos sujeitos da comunidade escolar consistiu em referendar essas metodologias que atrelam a melhoria da qualidade à melhoria de desempenho acadêmico.

\section{CONSIDERAÇÕES FINAIS}

No contexto de uma grande disputa em relação às políticas públicas para o Ensino Médio, última etapa da Educação Básica, este artigo analisa as implicações das novas abordagens de gestão, notadamente a democrática e a gerencial, na formação desenvolvida nessa etapa de ensino, na fase inicial da implantação do ProEMI (2009 a abril de 2013) em escolas de diferentes regiões do país. Para tanto, buscou identificar nas experiências relatadas por professores as relações entre os processos formativos e a gestão escolar.

O exame dos dados confirma a hipótese de que a abordagem gerencial dificultava a reformulação curricular na perspectiva da formação humana integral, prevista no Parecer CNE/CP n. 11/2009, que tratava da proposta de experiência curricular inovadora do Ensino Médio, e na Resolução CNE/SEB n. 2/2012, que instituiu as DCNEM em consonância com a Resolução CNE/CEB n. 4/2010, que definiu as Diretrizes Curriculares Nacionais Gerais para a Educação Básica.

A gestão democrática e os processos formativos, alinhados com essa perspectiva, foram a principal tendência observada nos relatos de experiência dos professores na implementação do ProEMI. O principal entrave ao fortalecimento da gestão democrática, princípio constitucional do ensino público, foi a adoção da tecnologia educacional PJF, do Instituto Unibanco. O PJF se baseia no conceito de Gestão Escolar para Resultados e foi concebido de acordo com os princípios da abordagem gerencial, um modelo de gestão que se pauta por parâmetros de qualidade, reconhecidos no meio empresarial.

Dado seu caráter instrumental, a tecnologia educacional PJF não possibilitava a efetiva participação dos sujeitos da escola no seu desenho. Estes tomavam parte apenas na sua execução de acordo com valores pré-estabelecidos pelos seus autores.

Com relação ao foco das práticas curriculares inovadoras relatadas pelos professores, as experiências alinhadas com a perspectiva democrática se preocupavam em garantir uma efetiva aprendizagem a todos os alunos em todas as áreas do conhecimento e componentes curriculares. Uma atenção 
especial foi dada àqueles que se encontravam em desvantagem na apropriação do conhecimento escolar, seja no processo de ensino-aprendizagem como um todo ou em aulas de recuperação ministradas por profissionais docentes.

Com base nos relatos dos professores é possível afirmar que a articulação entre as áreas de conhecimento possibilitou o desenvolvimento de práticas pedagógicas que se aproximavam da perspectiva de formação humana integral que o ProEMI buscava induzir. Em outra direção, as experiências curriculares marcadas pela abordagem gerencial associavam a melhoria da qualidade com a elevação dos índices de rendimento acadêmico. Mais especificamente, as práticas pedagógicas focalizavam o produto final do processo de ensino-aprendizagem e ressaltavam os resultados em avaliações externas como o ENEM e as avaliações estaduais, tais como SAERJ, SARESP, SPAECE e SIPAVE.

Por fim, a análise comparativa dos enfoques da abordagem democrática e gerencial elucidou que as disputas em torno da gestão do Ensino Médio estão diretamente relacionadas com o projeto educativo pretendido pelos grupos de interesse envolvidos.

\section{AGRADECIMENTOS}

Omitido.

\section{REFERÊNCIAS}

BARDIN, L. Análise de conteúdo. Lisboa, Portugal: Edições 70, 1977.

BRASIL. Parecer CNE/CP n. 11/2009. Trata da proposta de experiência curricular inovadora para o Ensino Médio. Brasília/DF, MEC/CNE, 30 jun. 2009a.

Portaria ministerial n. 971 de 09 de outubro de 2009. Institui o Programa Ensino Médio Inovador. Brasilia, DF, 09 de out. 2009b.

Programa Ensino Médio Inovador. Documento Orientador. Setembro2009c. Disponível em: <http://portal.mec.gov.br/dmdocuments/documento_ orientador.pdf $>$. Acesso em: 30 mar. 2013. 
. Guia de Tecnologias Educacionais. Aviso de Chamamento Público MEC/ SEB/SECAD/SEED/SEESP N. 1/2009. Pré-qualificação de Tecnologias que Promovam a Qualidade da Educação Básica. Diário Oficial da União, Brasília/ DF, seção 3, p. 41-44, 21 maio 2009d.

. Resolução n. 4, de 13 de julho de 2010. Define Diretrizes Curriculares Nacionais Gerais para a Educação Básica. Brasília, DF, MEC/CNE/CEB, 13 jul. 2010.

Parecer CNE/CEB n. 5 de 04 de maio de 2011. Estabelece as Diretrizes Curriculares Nacionais para o Ensino Médio. Brasília, DF, MEC/ CNE/CEB, 04 maio 2011a.

. Programa Ensino Médio Inovador. Documento Orientador. 2011b. Disponível em: http://portal.mec.gov.br/ dmdocuments/documento_ orientador.pdf. Acesso em: 26 mar. 2012.

. Edital n. 1, de 09 de dezembro de 2011. Pré-qualificação de tecnologias educacionais que colaborem para a ampliação da jornada escolar na perspectiva da educação integral e integrada e da articulação da escola com seu território. Diário Oficial da União, Brasília/DF, n. 237, seção 3, p. 32-38, 12 dez. 2011c.

Resolução CNE/SEB n. 02 de 30 de janeiro de 2012. Diretrizes Curriculares Nacionais para o Ensino Médio. Brasília, DF, MEC/CNE/SEB, 30 de jan. 2012.

. Lei 13.005, de 25 de junho de 2014. Aprova o Plano Nacional de Educação - PNE e dá outras providências. Disponível em: http://www.planalto. gov.br/ccivil_03/_Ato2011-2014/2014/Lei/L13005.htm. Acesso em: 07 maio 2015.

(Omitido).

CABRAL NETO, A.; CASTRO, A. M. D. A. Gestão escolar em instituições de ensino médio: entre a gestão democrática e a gerencial. Educação \& Sociedade, Campinas, v. 32, n. 116, p. 745-770, jul./set. 2011. 
DAYRELL, J.; CARRANO, P. Juventude e Ensino Médio: quem é este aluno que chega à escola. In: DAYRELL, J.; CARRANO, P.; MAIA, C. L. (Orgs.). Juventude e Ensino Médio: sujeitos e currículos em diálogo. Belo Horizonte: Editora UFMG, 2014, p. 101-133.

FERRETI, C. J.; ZIBAS, D. M. L. TARTUCE, G. L. B. P. Protagonismo juvenil na literatura especializada e na reforma do Ensino Médio. Cadernos de Pesquisa, v. 34, n. 122, p. 411-423, maio/ago. 2004.

(Omitido).

KRAWCZYK, N. Uma roda de conversa sobre os desafios do Ensino Médio. In: DAYRELL, J.; CARRANO, P.; MAIA, C. L. (Orgs.). Juventude e Ensino Médio: sujeitos e currículos em diálogo. Belo Horizonte: Editora UFMG, 2014, p. 75-98.

MINISTÉRIO DA EDUCAÇÃO (MEC). Como elaborar o Plano de Desenvolvimento da Escola; aumentando o desempenho da escola por meio do planejamento eficaz. 3 ed. Brasília: FUNDESCOLA/DIPRO/ FNDE/MEC, 2006.

Guia de Tecnologias Educacionais 2009. Organização Cláudio Fernando André. Brasília: Ministério da Educação, Secretaria de Educação Básica, 2009. $170 \mathrm{p}$.

Guia de Tecnologias Educacionais 2011/12. Organização COGETEC. Brasília: Ministério da Educação, Secretaria de Educação Básica, 2011. 196 p.

NOGUEIRA, M. A. A relação família-escola na contemporaneidade: fenômeno social/interrogações sociológicas. Análise Social, v. XL, n. 176, 2005, p. 563-578.

PAULA, A. P. P. Administração pública brasileira entre o gerencialismo e a gestão social. Revista de Administração de Empresas, v. 45, n. 1, 2005.

Por uma Nova Gestão Pública: limites e possibilidades da experiência contemporânea. Rio de Janeiro: FGV, 2007. 204 p. 
SAVIANI, D. O Plano de Desenvolvimento da Educação: uma análise do projeto do MEC. Educ. Soc., Campinas, v. 28, n. 100 - Especial, p. 1231-1255, out. 2007.

\section{Clecí Körbes}

Doutora em Tecnologia pela Universidade Tecnológica Federal do Paraná. Professora do Setor de Educação Profissional e Tecnológica da Universidade Federal do Paraná. E-mail: cleci.korbes@ufpr.br

\section{Monica Ribeiro da Silva}

Doutora em Educação pela Pontifícia Universidade Católica de São Paulo. Professora no Programa de Pós-graduação em Educação da Universidade Federal do Paraná. Coordenadora do Grupo de Pesquisa Observatório do Ensino Médio. Pesquisadora do CNPq. E-mail: monicars@ufpr.br

Recebido em: 02/10/2020

Aceito em: 01/11/2020 